\title{
The technological methods of surface layer modification in construction materials
}

\author{
Vladislav Smolentsev ${ }^{1, *}$, and Sergey Safonov ${ }^{1}$ \\ ${ }^{1}$ Voronezh State Technical University, Voronezh city, 394026 Moskovskiy prospect, 14, Russia
}

\begin{abstract}
The paper deals with the choice of a method and methodology of planning the technological processes to ensure the required quality of the surface layer of parts, resting on the principle of utility proposed by authors, which is an overall indicator of efficient use of external and internal impacts upon operational characteristics of products with modified surface layers: 1) the modification of properties without allowance removal, with a change in surface layer characteristics; 2) the removal of the allowance portion until reaching the material layer, having the desired operational characteristics; 3 ) the coating of products with surface layers, made from materials with desired characteristics and having a structure in which the operational properties are obtained by imparting the preset characteristics (wear resistance, heat resistance, etc.) to parts (including those made from other materials), applying the useful properties of coatings deposited; 4) the deposition of coatings comprising the inclusions of conductive and dielectric materials (e.g. ceramics, abrasives, etc.). The paper discovers the ways of using the principle of utility to justify the effectiveness and the scope of preferred application of technological processes of surface layer modification. It presents the methods of automation in selecting the technical means for enhancing the operational properties of high-tech products.
\end{abstract}

\section{Introduction}

When developing new methods and technologies, using the principle of utility [1], one should take into account that, along with the possibility to significantly improve the performance parameters of products by modifying the surface layer, there are limitations, one of which is the need to ensure the minimum cost and complexity of product manufacture. Such parameter is attained by optimized combinations of processing methods, the informed choice of base and coating materials, or surface processing, the way of producing the surface layer with specific operational requirements for products, and the cost of labour and materials for product manufacture. The criteria of the principle of utility underlie the methodology of planning new technological processes, which, for every area of problem development, becomes a foundation for setting new scientific trends in mechanical engineering, particularly, vibrowave technologies [2] and combined processing methods $[3,4,8]$.

In their works, the scientists of Voronezh have developed the program of scientifically informed choice and elaboration of new (mostly, at the level of inventions) methods of technological management of the surface layer quality to significantly improve the operational parameters of products. The program involves:

- the analysis of studies on the impact of materials upon the surface layer for improving the operational properties of products, with the study of well-known methods of surface layer modification and deposition of coatings using homogeneous and multicomponent materials. The result of this stage is a broad assessment of the useful effect of the surface layer upon attainment of higher operational parameters. The shortcomings of known methods and the level of their importance for final evaluation of the usefulness of technologies used have also been examined;

- the implementation of the principle of utility in manufacturing high-tech products $[4,5]$, involving the capacity analysis of enterprises of various forms of ownership, Russian and foreign scientists, universities, scientific and research institutes, design offices and the enterprises of small and medium-sized business. The result of this stage is technical-economical substantiation of the sequence of studies using the principle of utility;

- the rationale for the choice of overall numerical indicators of efficient use of the principle of utility for investigated methods of surface layer modification to attain higher performance indicators of products;

- the elaboration of the methodology for planning the combined technological processes $[6,7]$ on the basis of the principle of utility, combining several types of impacts which are most efficient for achieving the desired performance indicators of products [8]. Using the standard parts $[9,10]$, the analysis of expected results is conducted, suggesting the synthesis of compatible impacts among those really existing, being developed, or applied in industry.

The criteria for determining the usefulness of impacts upon the surface layer of products are shown in table 1.

\footnotetext{
* Corresponding author: enponomarenko@mail.ru
} 
Table 1. The criterial evaluation of the vector of utility for various technological impacts

\begin{tabular}{|c|c|c|c|c|c|c|c|c|}
\hline \multirow[b]{2}{*}{ Types of impacts } & \multirow[b]{2}{*}{ Methods of impact } & \multicolumn{7}{|c|}{$\begin{array}{l}\text { The vector of impacts upon performance characteristics of } \\
\text { products }(+- \text { rise, }-- \text { fall, } 0 \text { - no significant impact, oo - the } \\
\text { impact under special conditions })\end{array}$} \\
\hline & & $\begin{array}{l}\text { The } \\
\text { recovery } \\
\text { of initial } \\
\text { perfor- } \\
\text { mance } \\
\text { parame- } \\
\text { ters }\end{array}$ & $\begin{array}{l}\text { Heat } \\
\text { resistanc } \\
\quad \mathrm{e}\end{array}$ & & $\begin{array}{l}\operatorname{ar} \\
\operatorname{anc}\end{array}$ & $\begin{array}{l}\text { Fatigue } \\
\text { strength }\end{array}$ & $\begin{array}{l}\text { Protec- } \\
\text { tion } \\
\text { from } \\
\text { external } \\
\text { impacts }\end{array}$ & $\begin{array}{c}\text { Giving } \\
\text { new } \\
\text { operati } \\
\text { on } \\
\text { proper } \\
\text { ties }\end{array}$ \\
\hline \multirow{2}{*}{$\begin{array}{l}\text { Without surface } \\
\text { layer modification }\end{array}$} & $\begin{array}{l}\text { Chemical and thermal } \\
\qquad *\end{array}$ & 0 & 0 & \multicolumn{2}{|c|}{+} & + & + & oo \\
\hline & Vibro-hardening & 0 & 0 & \multicolumn{2}{|c|}{0} & + & 00 & 00 \\
\hline \multicolumn{9}{|l|}{ With removal of: } \\
\hline - allowance & $\begin{array}{l}\text { Mechanical** and } \\
\text { electromechanical*** } \\
\text { processing }\end{array}$ & + & 0 & \multicolumn{2}{|c|}{ oo } & - & - & + \\
\hline - coating & $\begin{array}{l}\text { Magnetovibrational } \\
\text { removal of thick } \\
\text { coatings }\end{array}$ & + & 0 & \multicolumn{2}{|c|}{ oo } & 0 & 0 & + \\
\hline \multicolumn{9}{|l|}{ With buildup of: } \\
\hline \multirow{3}{*}{$\begin{array}{c}\text { - a homogeneous } \\
\text { layer }\end{array}$} & $\begin{array}{l}\text { Electrospark } \\
\text { coating } * * * *\end{array}$ & 0 & + & + & - & \multicolumn{2}{|c|}{+} & + \\
\hline & Laser & 0 & + & + & 0 & \multicolumn{2}{|c|}{+} & + \\
\hline & Ion-plasma & 0 & 0 & + & 0 & \multicolumn{2}{|c|}{0} & + \\
\hline \multirow{3}{*}{$\begin{array}{l}\text { - a layer with pellet } \\
\text { inclusions }\end{array}$} & Laser & 0 & + & + & oo & \multicolumn{2}{|c|}{ oo } & oo \\
\hline & Ion-plasma & 0 & + & + & oo & \multicolumn{2}{|c|}{+} & oo \\
\hline & $\begin{array}{l}\text { Electrochemical } \\
\text { coating***** }\end{array}$ & oo & + & + & - & \multicolumn{2}{|c|}{0} & oo \\
\hline
\end{tabular}

It presents the broad criterial assessment of the main effects, some of which can alter the vector of impact depending upon application conditions of the method. The table 1 does not show the generally known technological methods (e.g. cementation, nitriding, cyanidation), having fairly full coverage in reference books [6, 7]. Most technological methods and impacts, presented in the table, are at the level of inventions and are being considered for the first time, since their application in perspective products is quite preferable.

When growing a homogeneous layer (table 1), it is possible to obtain new characteristics of materials while preserving or recovering the useful properties, evaluated by the utility coefficient, due to chemical and thermal impacts during coating of materials which do not have a high degree of protection from external factors (particularly, corrosion in aggressive media). It is necessary for engines operating on aggressive fuels.

The inclusion of pellets in coatings (table 1) provides an opportunity to impart their special operational characteristics to the whole product, maintaining the useful properties of the base material. This can be exemplified by deposition of the cast-iron hightemperature coating onto the fusible aluminium alloy, having the lower specific mass but little protection from effects of aggressive media and low wear resistance.
A more detailed presentation of operational characteristics of products with modified surface layer properties is given in $[5 ; 8]$.

The analysis of the impact of long-term studies of traditional and new technological processes upon the improvement of performance indicators of parts has shown the necessity for use of the available processing methods and their targeted integration into a single technological process, taking account of the operating conditions of parts in products $[1,2]$. When modifying the surface layer, one can impart the appropriate combination of operational characteristics to objects, which is not feasible under individual technological impacts, or such processes prove inefficient. The example of such impacts is chemical and electrochemical modification of a material layer, allowing to obtain the parts with new properties, e.g. those using the small weight base made of light alloys with hard cast-iron coating, having high durability and wear resistance, also at elevated operating temperatures. The quantitative estimates of the efficiency of proposed technological methods for standard operations of high-tech product manufacture are listed below. 


\section{The technological processes of surface layer modification}

The analysis of the impact of long-term studies of traditional and new technological processes upon the improvement of performance indicators of parts has shown the necessity for use of the available processing methods and their targeted integration into a single technological process, taking account of the operating conditions of parts in products $[1,2]$.

When modifying the surface layer, one can impart the appropriate combination of operational characteristics to objects, which is not feasible under individual technological impacts, or such processes prove inefficient. The example of such impacts is chemical and electrochemical modification of a material layer, allowing to obtain the parts with new properties, e.g. those using the small weight base made of light alloys with hard castiron coating, having high durability and wear resistance, also at elevated operating temperatures. The quantitative estimates of the efficiency of proposed technological methods for standard operations of high-tech product manufacture are listed below.

The coatings under review meet the highest standards in terms of the principle of utility when using technological processes involving deposition, removal or modification of the surface layer without allowance removal. The purpose of using such technological processes is to impart new operational properties to products, in particular, the manufacture of a part with minimal weight, high anti-friction rates and wear resistance of friction units (i.e. the parts made of aluminium alloy with cast-iron coating). The examples of such parts are drive shafts (e.g. those of the type presented in fig. 1). Here, there is a combination of aluminium alloys and steels with coatings ensuring the operation of a unit in strong oxidizers, which is only possible with surface protection of the material.

The greatest interest lies in the deposition of cast-iron coatings onto aluminium parts [8], allowing to obtain the properties of products, never achieved before, namely, minimization of mass along with high durability, protection from destruction and good anti-friction rates.

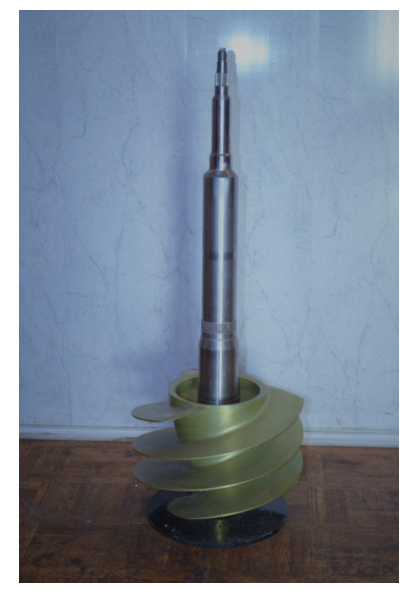

Fig. 1. A screw drive shaft for pumping aggressive media
The process of surface layer modification involving the allowance removal is used in bilateral processing of the working profile of aircraft jet engine blades (fig. 2).

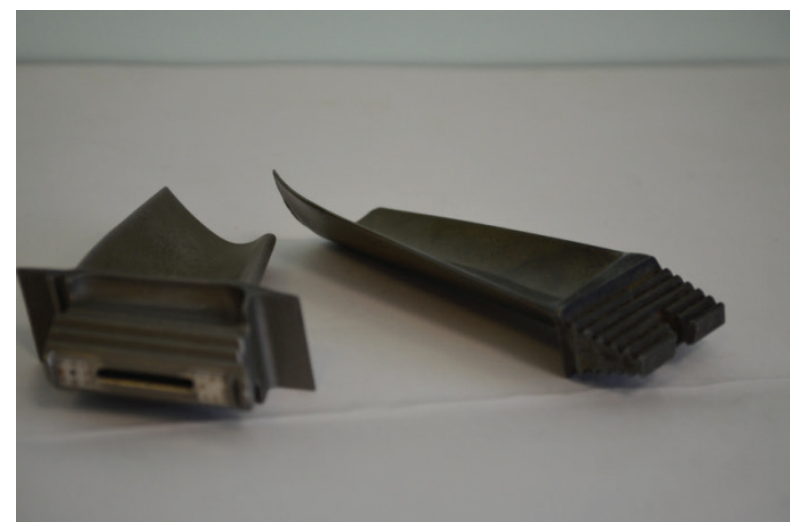

Fig. 2. Working blades of an aircraft engine turbine

After removing the modified layer from blade airfoils (fig.2) and depositing special coatings, it became possible to significantly increase the operational properties of parts and an engine as a whole, which is shown in table 2 .

In table $2 \overrightarrow{K_{1}}=\frac{\Pi_{p}}{\Pi_{o}} ; \overrightarrow{K_{2}}=\frac{\Pi_{\partial}}{\Pi_{o}}$, where $\Pi_{o}-$ is the performance indicator of a product without modifying the surface layer; $\prod_{p}-$ the post-modification indicator; $\prod_{\partial}-$ the indicator after elaboration and application of combined methods of modification, developed by authors.

When using the technological equipment for electrochemical processing, some of its elements are used to supply the electric current to a workpiece and can intensively dissolve, which causes a rapid loss of installation bases and the necessity for repair or replacement of tooling. The complexity of solving the problem consists in the fact that most metal protective coatings are subjected to anodic dissolution, while the deposited dielectric materials do not provide the supply of technological current. A new method of protecting the technological tooling from dissolution has been developed (The Author's Certificate of the USSR № 310772. The method of protecting current-carrying elements made of titanium alloys during electrochemical processing. The Bulletin of Inventions, 1971, № 24). The evaluation indicators of efficiency coefficients are presented above. 
Table 2. The improvement of operational properties of turbine blades

\begin{tabular}{|l|l|c|c|c|}
\hline \multicolumn{2}{|c|}{$\begin{array}{c}\text { The main } \\
\text { performance indicator }\end{array}$} & $\begin{array}{c}\text { The method of } \\
\text { impacting the surface } \\
\text { blade layer }\end{array}$ & $\overrightarrow{\mathrm{K}_{1}}$ & \multicolumn{2}{|c|}{$\begin{array}{c}\text { The results of surface } \\
\text { layer modification }\end{array}$} \\
\cline { 1 - 4 } $\begin{array}{l}\text { The increase of heat } \\
\text { resistance }\end{array}$ & $\begin{array}{l}\text { The removal of a } \\
\text { modified layer }\end{array}$ & $1,5 \div 2,0$ & $2,0 \div 3,0$ & $\begin{array}{l}\text { The rise of the } \\
\text { operating temperature } \\
\text { in front of the turbine } \\
\text { up to 200K }\end{array}$ \\
$\begin{array}{l}\text { The increase of fatigue } \\
\text { strength (lifetime) }\end{array}$ & Mechanical hardening & $1,1 \div 1,2$ & $1,2 \div 1,3$ & $\begin{array}{l}\text { The increase of the } \\
\text { product lifetime by } 10- \\
15 \%\end{array}$ \\
\hline
\end{tabular}

Table 3. The assessment of efficiency of the developed methods of protection from technological tooling dissolution

\begin{tabular}{|c|c|c|c|c|}
\hline \multirow{2}{*}{$\begin{array}{l}\text { Object of } \\
\text { processing }\end{array}$} & \multirow{2}{*}{$\begin{array}{l}\text { The method of surface } \\
\text { layer protection }\end{array}$} & \multicolumn{2}{|c|}{ Rates of efficiency } & \multirow{2}{*}{$\begin{array}{l}\text { The results of } \\
\text { surface layer } \\
\text { modification }\end{array}$} \\
\hline & & $\overrightarrow{\mathrm{K}_{1}}$ & $\overrightarrow{\mathrm{K}_{2}}$ & \\
\hline $\begin{array}{l}\text { The tooling for } \\
\text { processing the } \\
\text { blades of aircraft } \\
\text { engines }\end{array}$ & $\begin{array}{l}\text { The combined } \\
\text { processing in developed } \\
\text { technological modes }\end{array}$ & $1,2 \div 1,5$ & $1,5 \div 2,0$ & $\begin{array}{l}\text { The cost reduction } \\
\text { of tooling by } 15- \\
20 \%\end{array}$ \\
\hline $\begin{array}{l}\text { The tooling for } \\
\text { electrochemical } \\
\text { dimensional } \\
\text { processing of } \\
\text { helicopter blades }\end{array}$ & $\begin{array}{l}\text { The surface layer } \\
\text { transformations (the } \\
\text { Author's Certificate № } \\
\text { 310772) }\end{array}$ & $2,0 \div 3,0$ & $10 \div 30$ & $\begin{array}{l}\text { The increase of } \\
\text { tooling strength by } \\
80-90 \text { times; the } \\
\text { reduction of cost by } \\
18-20 \text { times }\end{array}$ \\
\hline
\end{tabular}

\section{Conclusion}

The discussion on the efficiency of using the principle of utility for forecasting the possibilities of surface layer modification in metals with the purpose of improving the operational properties of durable product parts has shown the following:

- the criterial evaluation based on the principle of utility can underlie the importance and efficiency of using the known and newly developed methods of surface layer modification, as well as planning the processes of coating deposition and removal. The result of this stage is broad assessment of the useful impact of surface layer modification upon the attainment of higher performance parameters;

- the examples of implementing the principle of utility when creating high-tech products have been shown;

- the system of numerical indicators of the principle of utility has been developed for modifying the surface layer and increasing the performance parameters of products.

\section{References}

1. E.V. Smolentsev, V.G. Gritsyuk, B.I. Omigov, The technological complexes for electrical processing methods (VSTU, Voronezh, 2015)

2. S.V. Safonov, S.N. Grigoriev, V.P. Smolentsev, The Bulletin of Voronezh State Technical University, 2, 19-26 (2015)

3. V.K. Sikka, S. Viswanathan, C.G. McKaamey, J. Struct. Intermetallics: Champion, 26-30 (1993)

4. A.M. Kadyrmetov, N.F. Kashapov, S.N. Sharifullin, A.I. Saifutdinov, S.A. Fadeev, IOP Conference Series: Materials Science and Engineering 134, 1-7 (2016)

5. V.V. Ivanov, V.A. Lebedev, I.A. Pinahin, J. of Friction and Wear, 35, 339-342 (2014)

6. V.I. Butenko, Structure and properties of the surface layer of tribosystem components (TTI JuFU, Taganrog, 2012)

7. E.V. Smolentsev, Planning of electrical and combined processing methods (Mashinostroenie, Moscow, 2005)

8. S.V. Safonov, V.P. Smolentsev, I.I. Koptev. J. Aircraft Engineering, 4, 72-75 (2016) 